\title{
Bookreview
}

\author{
H. E. Hess, E. Landolt and R. Hirzel
}

\section{BESTIMMUNGSSCHLÜSSEL ZUR FLORA DER SCHWEIZ UND ANGRENZENDER GEBIETE}

2. Auflage Birkhäuser Vorlag, Basel und Stuttgart 1984, 657 pp., 1277 Figs. Price SFr. 48. -

This identification key of pocket size (suitable for field work) is by the same authors as the voluminous Flora of Switzerland $(I-I I I)$, and fully derived from it in form and content. The typical feature of these works is the concept of species aggregate - a cluster of morphologically aimilar taxa, rather than a group of mutually related species.

Identification keys are dichotomous and indented - in some cases (e.g. in genera rich in species) this form seems rather impractical: tho distant antitheses (often on different pages) are not easily found; the traditional bracketed koy would very likely be more suitable. The identification key to the fumilies within the class (e.g. Dicotyledons) is divided into main groups, using subsidiary keys to reach the concreto taxa.

'The greater part of taxa are depicted. The Indian-ink marginal drawings usually represent general habits and/or distinguishing details (flowers, fruits, sceds). The book is supplemented by a brief morphological glossary, an Index of Latin namos of taxa with vernacular (Gorman) equivalents, and with German and Latin indices of the names of gonera.

It would be premature to appraise the booklet under roview - the quality of an identification key depends on its efficiency in field floristic work. Precisely printed figures, diacritic morphological features, brief notes on habitat or altitudinal range (rarely geographical distribution) are the data to be tested in this way. 